Revista de Educação e Pesquisa em Contabilidade Journal of Education and Research in Accounting Revista de Educación e Investigatión en Contabilidad
REPeC, Brasília, v. 6, n. 1, art. 1, p. 4-18, jan./mar. 2012

Disponível online em www.repec.org.br

ISSN 1981-8610

\title{
Análise do Disclosure dos Precatórios PÚblicos: InfluênCia da LegislaÇão e Fundamentos da TEORIa ContábIL
}

\author{
Lucas Oliveira Gomes Ferreira \\ Mestrando pelo Programa Multiinstitucional e Inter-Regional de Pós-Graduação em Ciências Contábeis UnB/UFPB/UFRN \\ Endereço: QNL 6 Conjunto H Casa 17 - Taguatinga, 72155-608 - Brasília, DF \\ E-mail: lucasogf@gmail.com
}

\section{Diana Vaz de Lima}

Doutoranda pelo Programa Multiinstitucional e Inter-Regional de Pós-Graduação em Ciências Contábeis UnB/UFPB/UFR Professora Assistente do Departamento de Ciências Contábeis e Atuariais da Universidade de Brasília - UnB

Endereço: Campus Universitário Darcy Ribeiro - Prédio da FACE - Salas B1-02 - Asa Norte, 70910-900 - Brasília, DF E-mail:diana_lima@unb.br

\section{Resumo}

A finalidade do estudo é analisar o disclosure dos precatórios públicos à luz da Teoria Contábil, além de verificar se a legislação vigente interfere no tratamento contábil desses valores. Nesse sentido, foi realizada pesquisa bibliográfica e documental sobre o arcabouço legal e procedimentos contábeis adotados e efetuada coleta de dados no Sistema de Coleta de Dados da Secretaria do Tesouro Nacional (SISTN), no período de 2004 a 2009, além de levantamento realizado pelo Supremo Tribunal Federal (STF) em 2004. A justificativa do estudo está na percepção de que mais da metade dos precatórios públicos não está registrada nas contas públicas. Como consequência, considerando que os precatórios configuram (1) direito líquido e certo ao requerente no processo e (2) dívida efetiva do ente público, a falta de disclosure prejudica tanto o beneficiado pela decisão judicial - que não vê refletido seu direito nas contas públicas e nem tem expectativa para recebimento, quanto o gestor governamental e a sociedade - que não dispõem de informações confiáveis que permitam gerenciar esses valores de maneira eficaz. A inovação consiste na discussão sobre a identificação do adequado momento do fato gerador dos precatórios públicos e da proposta de disclosure considerando a classificação de risco. Conclui que a influência da legislação vigente e a não observância dos fundamentos da doutrina contábil estão entre os prováveis fatores que têm afetado a adequada contabilização dos precatórios no âmbito da Administração Pública brasileira.

Palavras-Chaves: Precatórios Públicos; Disclosure; Contas Públicas.

Editado em Português, Inglês e Espanhol. Versão original em Português.

Recebido em 30/04/10. Pedido de Revisão em 04/03/11. Resubmetido em 06/05/11. Aceito em 07/05/11 por Valcemiro Nossa (Editor). Publicado em 27/03/12. Organização responsável pelo periódico: CFC/FBC/ABRACICON.

Copyright (C) 2012 REPEC. Todos os direitos, até mesmo de tradução, são reservados. É permitido citar parte de artigos sem autorização prévia, desde que seja identificada a fonte. 


\section{INTRODUÇÃO}

Levantamento realizado pelo Supremo Tribunal Federal em 2004 revelou que os processos judiciais transitados em julgado devidos pelos estados brasileiros totalizavam 41 bilhões de reais, mas apenas 14 bilhões de reais foram evidenciados nos Balanços Patrimoniais desses estados no exercício financeiro de 2005. Dos 26 estados e o Distrito Federal, 21 deles não apresentaram qualquer disclosure dos valores devidos em suas contas.

Considerando que esses valores conhecidos como precatórios configuram (1) direito líquido e certo ao requerente no processo e (2) dívida efetiva do ente público, a falta de disclosure prejudica tanto o beneficiado pela decisão judicial - que não vê refletido seu direito nas contas públicas e nem tem expectativa para recebimento -, quanto o gestor governamental e a sociedade - que não dispõem de informações confiáveis que permitam gerenciar esses valores de maneira eficaz.

Com base na competência, pressuposto básico da Contabilidade, o presente estudo teve como objetivo analisar o disclosure dos precatórios públicos à luz da Teoria Contábil, além de verificar se há influência da legislação vigente no tratamento contábil desses valores. A discussão se dá sobre a seguinte questão: a legislação vigente interfere no disclosure dos precatórios públicos? Os registros contábeis desses valores observam os fundamentos da doutrina contábil?

Para tratar essas questões, foi realizada pesquisa bibliográfica e documental sobre o arcabouço legal e procedimentos contábeis adotados, bem como efetuada coleta de dados no Sistema de Coleta de Dados da Secretaria do Tesouro Nacional (SISTN) no período de 2004 a 2009, além de considerar levantamento realizado pelo Supremo Tribunal Federal (STF) em 2004.

Para atender a questão de pesquisa, o artigo apresenta, além dessa introdução: (i) caracterização do precatório público; (ii) fundamentos contábeis e procedimentos relacionados; (iii) análise comparativa considerando os dados coletados do SISTN no período de 2004 a 2009, e levantamento realizado pelo STF em 2004; (iv) comentários finais com recomendações para os pesquisadores de Contabilidade Pública.

\section{CARACTERIZAÇÃO DO PRECATÓRIO PÚBLICO}

\subsection{Conceito de processos e precatórios judiciais}

Tem-se que o processo judicial consiste em todas as fases coordenadas regidas pelo direito processual, cujo primeiro ato é a petição inicial - a parte interessada reclama algum direito que julga ter sido violado -, e, o último, a sentença judicial transitada em julgado que constitui o precatório judicial (Figura 1):

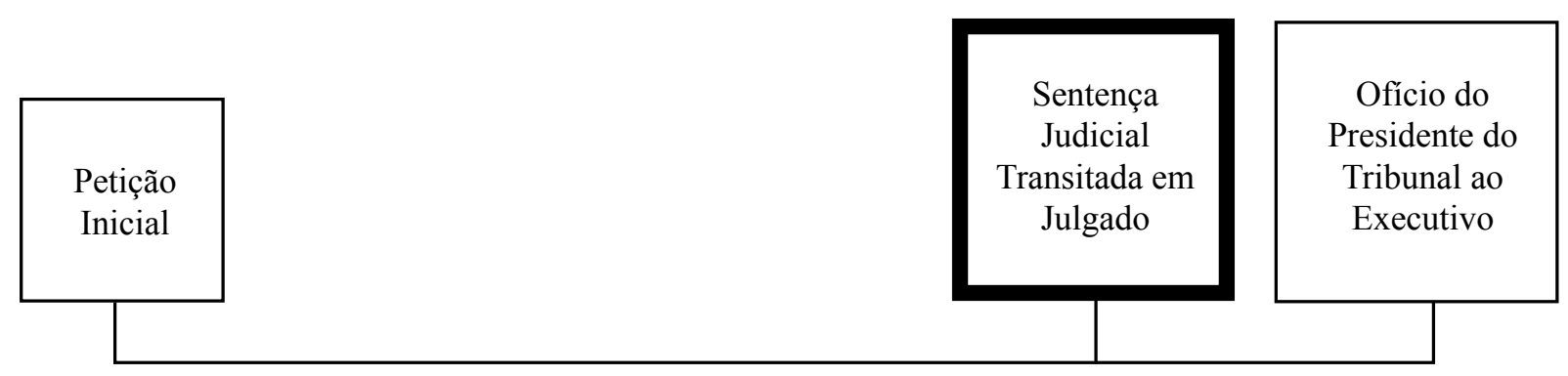

Figura 1 - Etapas do processo que geram o precatório

O precatório judicial caracteriza-se somente nos processos judiciais que determinam por meio da sentença judicial que a Administração Pública (Governo) pague o valor da sentença à parte requerente. $\mathrm{O}$ nascimento do precatório judicial se configura, pois, pela sentença judicial transitada 
em julgado, formalizada mediante encaminhamento de ofício do presidente do tribunal ao chefe do Poder Executivo.

Segundo Cunha (1986), o termo precatório é de etimologia obscura, derivado do latim precatorius. O Presidente do Tribunal que proferiu a decisão é a autoridade competente para determinar o pagamento integral e autorizar o sequestro da quantia respectiva, nos termos da Constituição Federal do Brasil de 1988.

Conforme Harada (2008, p. 24), precatório judicial é a requisição de pagamento (solicitação com sentido de ordem) do montante da condenação judicial feita pelo Presidente do Tribunal que proferiu a decisão objeto de execução contra a Fazenda Pública, representada pela União, Estados, DF ou Municípios, por conta de verba consignada na Lei Orçamentária Anual (LOA) diretamente ao Poder Judiciário.

Portanto, o termo precatório configura-se sob a forma de processo judicial transitado em julgado, caracterizando-se, em termos contábeis, como um Ativo para o detentor do direito a receber, e um passivo para a Administração Pública (Governo), que tem o dever de pagar.

No Governo, as dotações orçamentárias e os créditos abertos para pagamento dos precatórios são consignados diretamente ao Poder Judiciário (CF 1988, art. 100, $\S 2^{\circ}$ ). Assim, após o trânsito em julgado, o Presidente do Tribunal, por meio de ofício, informa ao Poder Executivo a existência do precatório.

\subsection{Classificação de precatórios judiciais}

Os precatórios judiciais classificam-se em débitos de natureza alimentícia e débitos de natureza não alimentícia. O art. 100 da Constituição Federal do Brasil de 1988 tipifica apenas os precatórios relativos a débito de natureza alimentícia:

$\S 1^{\circ} \mathrm{A}$ - Os débitos de natureza alimentícia compreendem aqueles decorrentes de salários, vencimentos, proventos, pensões e suas complementações, benefícios previdenciários e indenizações por morte ou invalidez, fundadas na responsabilidade civil, em virtude de sentença transitada em julgado (BRASIL, 1988).

Logo, todos os precatórios que não se enquadrarem no conceito de débitos de natureza alimentícia serão considerados débitos de natureza não alimentícia. No Plano de Contas do Sistema Integrado de Administração Financeira do Governo Federal (SIAFI), os precatórios a pagar estão segregados em quatro itens de contas distintos, quais sejam: pessoal, fornecedores, terceiros e benefícios.

A Constituição Federal de 1988 estabelece que à exceção dos créditos de natureza alimentícia, que terão prioridade, os pagamentos devidos pela Fazenda Pública serão feitos em observância à ordem cronológica de apresentação dos precatórios.

Os pagamentos de precatórios ou requisições de pequeno valor (denominados RPVs), cujos valores variam de 30 a 60 salários mínimos, possuem rito de pagamento mais rápido do que os demais precatórios. A celeridade do seu pagamento, contudo, dependerá da capacidade econômica das entidades de direito público (BRASIL, CF, art. 100, $\S 5^{\circ}$ ):

\begin{tabular}{|l|c|c|c|}
\hline Entes da Federação & \multicolumn{3}{|c|}{ Limites Salários-mínimos } \\
\hline União & 60 & - & - \\
\hline Estados/DF & - & 40 & - \\
\hline Municípios & - & - & 30 \\
\hline
\end{tabular}

Quadro 1 - Precatórios caracterizados como RPVs

Fonte: Resoluções do Senado Federal no 40 e 43 de 2001 
Ressalta-se que é vedada a expedição de precatório complementar ou suplementar de valor pago, bem como fracionamento, repartição ou quebra do valor da execução (CF, art. $\left.100 \S 4^{\circ}\right)$. O objetivo desse dispositivo legal é evitar que o pagamento de precatório se faça, em parte, na forma de requisição de pequeno valor e, em parte, mediante expedição de precatório.

\subsection{Dos aspectos orçamentários}

O pagamento dos precatórios, como das demais despesas públicas, segue determinado rito orçamentário, passando pela autorização legislativa (dotação especifica na Lei Orçamentária Anual LOA) até o cumprimento dos estágios do empenho, da liquidação e do pagamento.

Dependendo da avaliação de risco, os processos judiciais podem ser caracterizados como passivo desde sua origem. Entretanto, na prática, somente os processos judiciais sob a forma de precatórios - ou seja, aqueles transitados em julgado, em que não cabe mais nenhum recurso judicial - são incluídos na LOA.

A legislação ainda estabelece que para serem incluídos na elaboração da LOA, os precatórios devem ser apresentados até $1^{\circ}$ de julho de cada exercício (CF 1988, art. $100 \S 1^{\circ}$ ). Com isso, se a decisão judicial ultrapassar esse prazo, o precatório deverá aguardar o prazo de elaboração da LOA do exercício seguinte. Contemplado finalmente na LOA, o pagamento deverá ocorrer até o final de sua vigência, quando terão seus valores atualizados monetariamente. A Figura 2 representa em linha temporal a inclusão de precatórios na LOA:

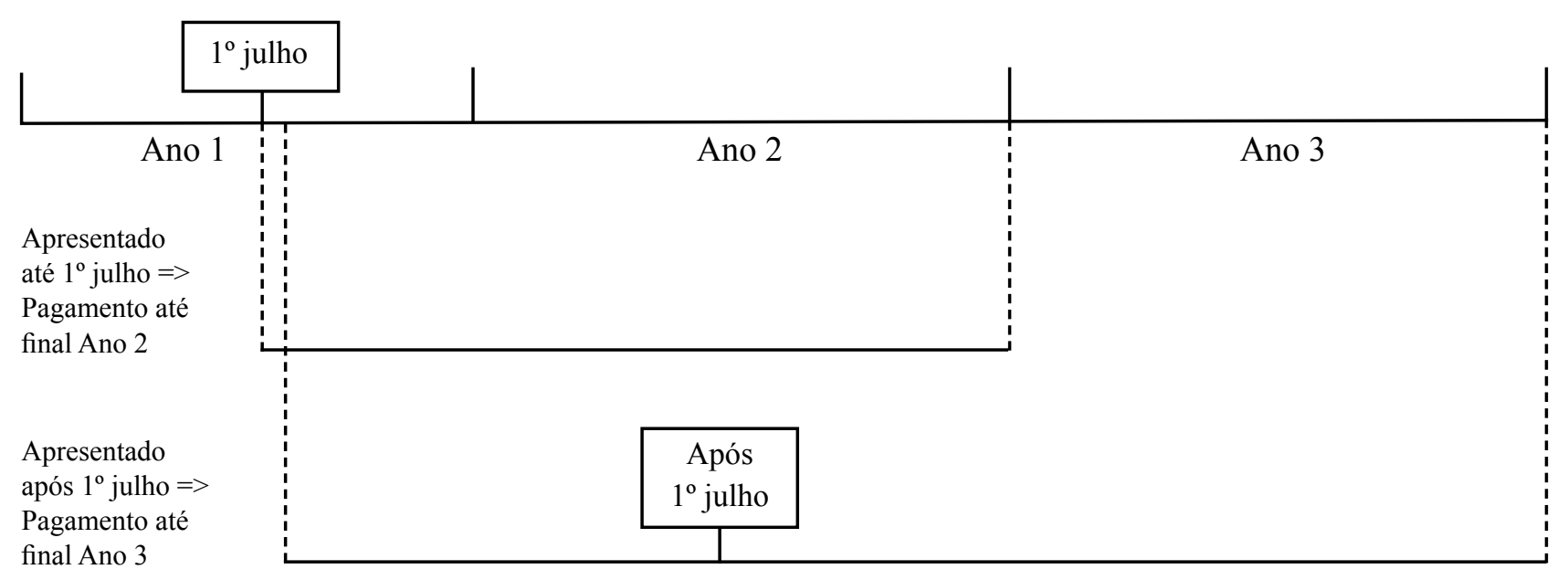

Figura 2 - Inclusão dos precatórios no orçamento

Observa-se que o pagamento de um precatório apresentado até $1^{\circ}$ de Julho do Ano 1 leva em torno de 18 meses para sua execução orçamentária e financeira. Após esse dia, o precatório apresentado será incluído apenas na LOA do ano seguinte e executados dois anos depois, estendendo o prazo inicial de 18 para 30 meses.

Há iniciativas com o objetivo de ampliar o prazo do pagamento dos precatórios e, consequentemente, diminuir seus efeitos sobre as contas públicas, como os Atos das Disposições Constitucionais Transitórias (ADCT), arts. 33 e 78, editados em 1989 e 1999, respectivamente.

O primeiro Ato fixou prazo máximo de oito anos para pagamento dos precatórios judiciais pendentes de pagamento na data da promulgação da Constituição (5/10/1988), contados a partir de $1^{\circ}$ de julho de 1989 (ADCT art. 33 caput). O segundo Ato determinou a liquidação pelo valor real, em moeda corrente, corrigido por juros estabelecidos em lei, em prestações anuais, iguais e sucessivas, até o prazo máximo de dez anos dos precatórios pendentes na data de promulgação da Emenda Constitucional N. 30 de 14/9/2000 e dos que decorram de ações iniciais ajuizadas até 31 de dezembro de 1999. 


\subsection{Dos limites da LRF}

De acordo com o disposto no art. 30, $\S 7^{\circ}$, da Lei Complementar N. 101/2000, Lei de Responsabilidade Fiscal (LRF), os precatórios judiciais não pagos durante a execução do orçamento no ano em que foram incluídos integram a dívida consolidada para fins de aplicação dos limites.

Nesse caso, entende-se por limite o nível máximo de endividamento permitido para o ente público. Assim, ao incluir os precatórios judiciais nessa base de valores, automaticamente o nível de endividamento é afetado. A Lei também estabelece que o ente que ultrapassar o limite estabelecido na lei, e, enquanto perdurar o excesso, ficará proibido de realizar operação de crédito interna ou externa, inclusive por antecipação de receita, ressalvado o refinanciamento do principal atualizado da dívida mobiliária. Além disso, vencido o prazo para retorno da Dívida ao limite, e, enquanto perdurar o excesso, o ente ficará também impedido de receber transferências voluntárias da União ou do Estado (LRF, art. 31, $\S \S 1^{\circ}$ e $2^{\circ}$ ).

Como se pode observar, as exigências da LRF podem afetar a decisão do gestor em registrar contabilmente os precatórios públicos em sua integralidade, já que esse processo de disclosure gera ônus para as contas do respectivo ente público. Por outro lado, a omissão dessa informação nos limites da dívida consolidada pode fazer com que as informações sobre precatórios judiciais disponíveis nos balanços públicos sejam ainda mais distantes dos seus respectivos números reais.

\subsection{Das mudanças na legislação}

Devido às dificuldades enfrentadas pelos entes públicos para honrar o pagamento dos precatórios sob sua responsabilidade, os parlamentares brasileiros vêm discutindo propostas de novas legislações que possibilitem mudanças nas regras atuais, como a vinculação dos pagamentos a determinado percentual da receita corrente líquida, pagamentos via leilão de deságio, entre outros.

Em 2009, foi promulgada a Emenda Constitucional N. 62 de 2009, trazendo, entre outros, a inclusão de idosos e portadores de doenças graves na preferência do pagamento de precatórios e a vinculação de porcentagens da receita corrente líquida dos entes para pagamento de precatórios. Contudo, mudanças como essa sofrem forte resistência da comunidade jurídica, que considera que a medida representa, na prática, um calote, ferindo direitos adquiridos judicialmente, uma vez que os precatórios já representam decisões transitadas em julgado.

Na prática, a vinculação da receita corrente líquida obriga os entes a reservarem uma margem exclusiva para os precatórios, mas, ao mesmo tempo, a limitação por meio de percentual previamente estabelecido protela o pagamento dos valores devidos. Como resultado, os pagamentos que ultrapassarem o percentual fixado passam a ser acumulados com as novas sentenças e pela incidência de juros e atualização monetária, além da ansiedade e insatisfação dos que aguardam o recebimento.

\section{TRATAMENTO CONTÁBIL DOS PRECATÓRIOS PÚBLICOS}

\subsection{Caracterização do precatório como passivo}

Como visto anteriormente, da perspectiva do Governo, o precatório representa uma condenação judicial feita pelo Presidente do Tribunal que proferiu a decisão objeto de execução contra a Fazenda Pública, constituindo, pois, um passivo. Segundo Lapsley (1988), o esforço mais significativo de pesquisadores de Contabilidade tem sido direcionado para a prestação de contas, portanto, o adequado disclosure do passivo é uma forma de prestação de contas à sociedade.

A Contabilidade Pública recepcionou considerável parte da Teoria Contábil que trata de passivo por meio da Portaria STN n ${ }^{\circ} 664$, de 30 de novembro de 2010, que instituiu a terceira edição do Manual de Contabilidade Aplicada ao Setor Público. Segundo o Manual, o passivo é reconhecido no balanço patrimonial quando for provável que uma saída de recursos envolvendo benefícios econômicos seja exigida em liquidação de uma obrigação presente e o valor pelo qual essa liquidação se dará possa ser determinado em bases confiáveis (STN, 2010, p. 15). 


\section{repec}

No quadro 2 é possível observar como as características dos precatórios judiciais enquadramse na definição de passivos:

\begin{tabular}{|l|l|l|}
\hline & Precatórios & Passivos \\
\hline 1 & $\begin{array}{l}\text { Contém uma obrigação, porque a sentença judicial já } \\
\text { transitou em julgado. Logo, há determinação judicial } \\
\text { (coercitiva) que o Estado pague dívida presente. Mas } \\
\text { mesmo antes da decisão transitar em julgado, desde que } \\
\text { seja comprovada por órgão competente que é 100\% pro- } \\
\text { vável que a decisão judicial será contra o Estado, já con- } \\
\text { figura responsabilidade presente. }\end{array}$ & $\begin{array}{l}\text { Contém uma obrigãa ou responsabilidade presente } \\
\text { com uma ou mais entidades, prevendo liquidação pela } \\
\text { transferência futura provável ou pelo uso de ativos numa } \\
\text { data especificada ou determinável, na ocorrência de um } \\
\text { evento prederminado, ou assim que seja solicitada. }\end{array}$ \\
\hline 2 & $\begin{array}{l}\text { O Estado não tem capacidade de evitar a decisão transi- } \\
\text { tada em julgado. O que for determinado pelo juiz, deve } \\
\text { ser seguido. }\end{array}$ & $\begin{array}{l}\text { A obrigação ou responsabilidade compromete dada enti- } \\
\text { dade, permitindo-lhe pouca ou nenhuma liberdade para } \\
\text { evitar o sacrifício futuro. }\end{array}$ \\
\hline 3 & $\begin{array}{l}\text { O objeto de processo judicial sempre é com base em } \\
\text { evento passado, já ocorrido. }\end{array}$ & $\begin{array}{l}\text { A transação ou outro evento que obriga a entidade já } \\
\text { ocorreu. }\end{array}$ \\
\hline
\end{tabular}

\section{Quadro 2 - Precatórios versus passivos}

Para Niyama e Silva (2008, p. 149), uma questão importante na definição de passivo é também saber se é necessário para o seu reconhecimento que o benefício econômico a ser liquidado seja suficientemente negativo, devendo ainda ser considerado se o passivo é certo ou se é probabilístico.

O pronunciamento SFAS 5 - Accounting for Contingencies emitido pelo FASB, conceitua contingência como uma condição existente, situação ou conjunto de circunstâncias envolvendo incerteza quanto ao possível ganho ou perda para uma empresa, que será resolvido quando um ou mais eventos futuros ocorrerem ou deixarem de ocorrer. Uma perda de contingência deverá ser reconhecida no resultado se a informação disponível antes da emissão das demonstrações financeiras indica que é provável o comprometimento de um ativo ou a incorrência de um passivo contido nessa condição, que deve ser provável que um ou mais eventos futuros ocorram confirmando o fato da perda, e se o o montante da perda pode ser razoavelmente estimado (SFAS 5).

Segundo a IPSAS 19 - Provisions, Contingent Liabilities and Contingent Assets, provisão é um passivo de prazo ou valor incertos e deve ser reconhecida quando a entidade tem uma obrigação presente (legal ou não formalizada) como resultado de evento passado, quando seja provável que será necessária uma saída de recursos que incorporam benefícios econômicos ou potencial de serviços para liquidar a obrigação e quando uma estimativa confiável possa ser feita do montante da obrigação. Caso essas condições não sejam satisfeitas, nenhuma provisão deve ser reconhecida.

Conceitualmente, passivo contingente é segundo a IPSAS 19 uma obrigação possível que resulta de eventos passados e cuja existência será confirmada apenas pela ocorrência ou não de um ou mais eventos futuros incertos não totalmente sob controle da entidade. Também é considerada passivo contingente obrigação presente que resulta de eventos passados, mas que não é reconhecida, porque não é provável que uma saída de recursos que incorporam benefícios econômicos ou potencial de serviços seja exigida para liquidar a obrigação, ou o valor da obrigação não pode ser mensurado com suficiente confiabilidade (IPSAS 19, parágrafo 18).

Dessa forma, o passivo contingente não deve ser reconhecido porque não é provável que uma saída de recursos que incorporam benefícios econômicos seja exigida para liquidar a obrigação ou o valor da obrigação não pode ser mensurado com suficiente confiabilidade. A probabilidade de ocorrência e sua magnitude dependem de condições exógenas cuja ocorrência é difícil de prever (Lei N. 11.768/2009, Anexo VI, p. 217).

A IPSAS 19 considera que provisões são contingentes porque são incertas quanto ao seu prazo ou valor, mas serão reconhecidas como passivo exatamente porque são obrigações presen- 
tes e presume-se que possa ser feita uma estimativa confiável. Porém, os passivos contingentes não são reconhecidos porque a sua existência somente será confirmada pela ocorrência ou não de um ou mais eventos futuros incertos, não totalmente sob o controle da entidade. O Quadro 3 resume a determinação da IPSAS 19 quanto ao reconhecimento e disclosure da provisão e passivo contingente.

\begin{tabular}{|c|c|c|}
\hline \multicolumn{3}{|c|}{$\begin{array}{l}\text { Quando, em conseqüência de eventos passados, possa existir uma saída de recursos incorporando benefícios } \\
\text { econômicos futuros ou potencial de serviços na liquidação de: (a) uma obrigação presente; ou (b) uma possível } \\
\text { obrigação cuja existência seja confirmada somente pela ocorrência ou não ocorrência de um ou vários eventos } \\
\text { futuros incertos que não são totalmente controlados pela entidade. }\end{array}$} \\
\hline & $\begin{array}{l}\text { Há obrigação possível ou uma obriga- } \\
\text { ção presente que possa, mas prova- } \\
\text { velmente não irá, exigir uma saída de } \\
\text { recursos. }\end{array}$ & $\begin{array}{l}\text { Há uma possível obrigação ou uma } \\
\text { obrigação presente onde a probabilida- } \\
\text { de de uma saída dos recursos é remota. }\end{array}$ \\
\hline A Provisão é reconhecida (parágrafo 22). & $\begin{array}{l}\text { Nenhuma provisão é reconhecida } \\
\text { (parágrafo 35). }\end{array}$ & $\begin{array}{l}\text { Nenhuma provisão é reconhecida } \\
\text { (parágrafo 35). }\end{array}$ \\
\hline $\begin{array}{l}\text { Disclosure da provisão é necessário } \\
\text { (parágrafos } 97 \text { e } 98 \text { ). }\end{array}$ & $\begin{array}{l}\text { Disclosure do passivo contingente é } \\
\text { necessário (parágrafo 100) }\end{array}$ & $\begin{array}{l}\text { Disclosure não é necessário (parágra- } \\
\text { fo } 100 \text { ). }\end{array}$ \\
\hline
\end{tabular}

\section{Quadro 3 - Provisão e passivo contingente}

Fonte: Adaptado de IPSAS 19 Apêndice A

A IPSAS 19 determina que disclosure sobre os passivos contingentes é exigido no caso de obrigação possível e provável (Quadro 3) e ressalta que um passivo contingente também surge em casos extremamente raros na existência de um passivo que não pode ser reconhecido porque não pode ser precisamente mensurado.

A interpretação de expressões de incerteza como as da IPSAS 19 (obrigação remota, possível e provável) não é simples e objetiva de se determinar, mas é informação relevante. Os resultados do estudo de Du e Steven (2010, p. 259) sugerem que fornecer aos auditores e elaboradores de demonstrações financeiras (contadores) orientações numérica-para-verbal melhora a consistência do julgamento desses profissionais. Assim, definindo previamente termos como provável ou razoavelmente possível ajuda a garantir que tanto auditores e contadores entendam o que esses termos significam antes da emissão demonstrações financeiras (DU; STEVEN, 2010).

Tem-se, portanto, a necessidade de classificar adequadamente o precatório judicial, para estabelecer o procedimento contábil de disclosure que reflita a natureza da transação, ou seja, se haverá ou não reconhecimento da provisão e como deverá ser o disclosure desses valores nas contas públicas. Por meio de dois experimentos distintos com estudantes, Du e Steven (2010, p. 257) verificaram que a tradução numérica-para-verbal permite a identificação de três categorias de decisão para perda contingente: remota, razoavelmente possível e provável.

Para Windschitl e Wells (1996), mensurações verbais de incerteza podem ser mais sensíveis ao contexto e à manipulação de enquadramento que as mensurações numéricas. Logo, a classificação da probabilidade de ocorrência de um processo judicial é de extrema importância e necessita de critérios objetivos de classificação para evitar influência de outros fatores, como o verificado pelos autores. Esses critérios aproximam o Setor Público de práticas à luz da Teoria Contábil e representa um avanço no âmbito da Administração Pública, que se junta a procedimentos já adotados, como os indicadores de desempenho devidamente presentes no Setor Público há vários anos (Smith, 1990).

A causa de erros de tratamento contábil muitas vezes ocorre em função do próprio Governo. Esse tipo de situação foi comprovado por Lapsley (1988), que verificou que as organizações públicas do Reino Unido eram orientadas erroneamente pelo Governo Central quanto à avaliação de investimento do Setor Público. 
Essa prática é comum nos países baseados no modelo code-law, que segundo Flower (2002) é um modelo que possui como característica a forte influência governamental no estabelecimento de padrões contábeis. Du e Stevens (2010) ressaltam que o fornecimento de orientação numérica-paraverbal melhora a consistência do julgamento

Alguns estudos, como de Reimers (1992), Nelson e Kinny (1997), Hoffman e Patton (2002) e Aharony e Dotan (2004), apontam que as probabilidades numéricas atribuídas pelos auditores variam muito e sua interpretação pode ser facilmente influenciada por informações contextuais. Se a atribuição dos auditores varia, o mesmo pode ocorrer com os responsáveis pela elaboração dos relatórios públicos. Assim, há necessidade de regulamentação que minimize as diferenças de interpretação na aplicação das expressões verbais de probabilidade.

Acerca da mensuração, o Anexo de Riscos Fiscais da Lei de Diretrizes Orçamentárias referente ao exercício de 2009 estabelece que tendo clara a dificuldade de prever o resultado final de um conjuncto de ações que supostamente ofereçam risco ao Erário, como no caso dos processos judiciais, caberia à Advocacia Geral da União (AGU) a responsabilidade de se fazer uma estimativa quanto a possíveis valores de condenação (Lei 11.768/2009, Anexo VI, p. 222).

\subsection{Estabelecimento do fato gerador}

A Resolução CFC N. 1.121/08, que traz a estrutura conceitual para elaboração e apresentação das demonstrações contábeis, estabelece dois pressupostos básicos da Contabilidade. O primeiro é o regime de competência que reconhece os efeitos das transações e outros eventos quando ocorrem, e não quando o caixa é afetado e outros recursos financeiros são recebidos ou pagos. Assim, tais efeitos e outros eventos são lançados nos registros contábeis e reportados nas demonstrações contábeis dos períodos a que se referem. Esse regime pressupõe a confrontação entre receitas e despesas. O segundo pressuposto é a continuidade, no qual a entidade continuará em operação no futuro previsível.

A rigor, dependendo da classificação de risco que acompanha um processo judicial, esses valores deverão ser reconhecidos no momento em que o passivo esteja caracterizado, ou seja: obrigação atual, resultante de eventos passados e cuja liquidação resulte em desembolso de benefícios econômicos para a entidade.

Contudo, a recomendação constante do Manual de Contabilidade Aplicada ao Setor Público da STN é que a contabilização dos precatórios seja feita logo após a decisão judicial transitada em julgado, prevalecendo, consequentemente, o fato gerador jurídico em detrimento do fato gerador contábil. Na prática, porém, a situação é bastante controversa, já que o disclosure dos precatórios ocorre apenas quando da inclusão dos precatórios judiciais na LOA (Figura 3):

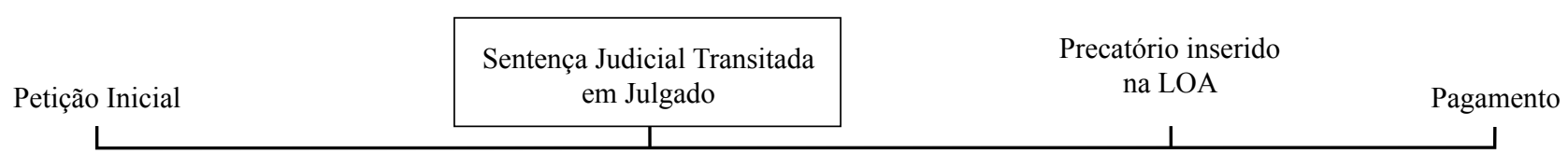

\section{Figura 3 - Fluxo temporal de reconhecimento de processos judiciais}

Tem-se, portanto, a discussão do que vem a ser efetivamente o fator gerador do precatório público: se orçamentário, contábil ou jurídico (Quadro 4):

\begin{tabular}{|c|l|l|}
\hline Orçamentário & \multicolumn{1}{|c|}{ Contábil } & \multicolumn{1}{c|}{ Jurídico } \\
\hline $\begin{array}{l}\text { Momento da inclusão } \\
\text { do precatório na LOA. }\end{array}$ & $\begin{array}{l}\text { Momento da caracterização do passivo: obrigação atual, } \\
\text { resultante de eventos passados e cuja liquidação resulte em } \\
\text { desembolso de benefícios econômicos para a entidade. }\end{array}$ & $\begin{array}{l}\text { Requisição de pagamento (solicitação } \\
\text { com sentido de ordem) do montante } \\
\text { da condenação judicial. }\end{array}$ \\
\hline
\end{tabular}

Quadro 4 - Fato gerador do precatório judicial 
A máxima que vem configurando a fase entre a decisão judicial transitada em julgado e a previsão orçamentária é: “devo não nego, pago quando o orçamento permitir.” Ressalta-se que, de acordo com os fundamentos da Teoria Contábil, o registro do precatório judicial deve considerar o momento da caracterização do passivo, e prevalecer, portanto, para fins de registro nas contas públicas, o fato gerador contábil.

\section{METODOLOGIA}

O presente estudo teve como objetivo analisar o disclosure dos precatórios públicos à luz da Teoria Contábil, além de verificar se há influência da legislação vigente no tratamento contábil desses valores e se o registro contábil dos precatórios públicos reflete a realidade dos compromissos devidos pelo Governo brasileiro. Nesse sentido, será efetuada análise do disclosure dos precatórios nos balanços públicos brasileiros. Comparando o valor levantado pelo órgão central do judiciário, que tem acesso a todos os processos em trâmite no país, com os dados dos balanços públicos do governo (dados de fontes distintas) é possível verificar se está havendo ou não o adequado disclosure dos precatórios à luz da Teoria Contábil.

Mediante análise dos dados, verificar-se-á se o disclosure dos precatórios de responsabilidade dos Estados e Governo Federal brasileiro reflete os valores das decisões transitadas em julgado. Para tratar essas questões, foi desenvolvida uma análise tendo como base pesquisa bibliográfica e documental e efetuada coleta de dados do Sistema de Coleta de Dados da Secretaria do Tesouro Nacional (SISTN) no período de 2004 a 2009, além de considerar levantamento realizado pelo Supremo Tribunal Federal (STF) em 2004.

É importante ressaltar que a análise considerou os dados do STF relativos ao exercício de 2004 (Tabela 1) por ser esse o único ano em que foi realizado levantamento nacional dos precatórios judiciais brasileiros pendentes de pagamentos, informação confirmada pelo Conselho Nacional de Justiça - CNJ, que, em consulta, disse não haver nenhuma previsão para que seja realizado novo levantamento pelos tribunais do país.

\section{Tabela 1 - Valores em R\$ do STF de 2004}

\begin{tabular}{|c|c|c|c|c|}
\hline UF & Estado & Estados & Capitais & Total \\
\hline $\mathrm{AC}$ & Acre & 109.979 .181 & 47.221 .380 & 157.200 .561 \\
\hline $\mathrm{AL}$ & Alagoas & 55.234 .297 & 149.025 .962 & 204.260 .259 \\
\hline $\mathrm{AM}$ & Amazonas & 36.513 .866 & 116.574 .237 & 153.088 .103 \\
\hline $\mathrm{AP}$ & Amapá & 27.325 .049 & 2.635 .679 & 29.960 .728 \\
\hline $\mathrm{BA}$ & Bahia & 557.687 .758 & 518.521 .027 & 1.076 .208 .785 \\
\hline $\mathrm{CE}$ & Ceará & 469.872 .201 & 90.176 .859 & 560.049 .060 \\
\hline $\mathrm{DF}$ & Distrito Federal & 2.429 .178 .278 & 10.099 & 2.429 .188 .377 \\
\hline ES & Espírito Santo & 6.975 .143 .012 & 1.090 .630 .122 & 8.065 .773 .134 \\
\hline $\mathrm{GO}$ & Goiás & 906.816 .446 & 140.250 .992 & 1.047 .067 .437 \\
\hline MA & Maranhão & 72.155 .114 & 75.149 .619 & 147.304 .732 \\
\hline $\mathrm{MG}$ & Minas Gerais & 3.500 .000 .000 & 733.456 .201 & 4.233 .456 .201 \\
\hline $\mathrm{MS}$ & Mato Grosso do Sul & 276.857 .910 & 45.688 .796 & 322.546 .706 \\
\hline MT & Mato Grosso & 2.223 .516 .347 & 375.279 .490 & 2.598.795.837 \\
\hline $\mathrm{PA}$ & Pará & 0 & 11.851 .165 & 11.851 .165 \\
\hline $\mathrm{PB}$ & Paraíba & 139.780 .417 & 41.132 .608 & 180.913 .025 \\
\hline $\mathrm{PE}$ & Pernambuco & 83.795 .302 & 82.106 .953 & 165.902 .255 \\
\hline PI & Piauí & 139.758 .472 & 29.564 .853 & 169.323 .325 \\
\hline
\end{tabular}




\begin{tabular}{l|l|r|r|r}
\hline PR & Paraná & 6.940 .496 .196 & 4.560 .640 .553 & 11.501 .136 .749 \\
\hline RJ & Rio de Janeiro & 1.322 .801 .847 & 303.485 .459 & 1.626 .287 .306 \\
\hline RN & Rio Grande do Norte & 112.409 .055 & 176.178 .116 & 288.587 .171 \\
\hline RO & Rondônia & 318.822 .635 & 122.175 .311 & 440.997 .946 \\
\hline RR & Roraima & 2.043 .722 & 6.558 .060 & 8.601 .783 \\
\hline RS & Rio Grande do Sul & 2.329 .490 .913 & 194.399 .508 & 2.523 .890 .422 \\
\hline SC & Santa Catarina & 300.002 .604 & 122.759 .411 & 422.762 .015 \\
\hline SE & Sergipe & 71.831 .234 & 64.580 .152 & 136.411 .385 \\
\hline SP & São Paulo & 12.224 .298 .358 & 10.887 .306 .103 & 23.111 .604 .461 \\
\hline TO & Tocantins & 11.373 .964 & 10.126 .502 & 21.500 .466 \\
\hline BR & Total & 41.637 .184 .177 & 19.997 .485 .217 & 61.634 .669 .394 \\
\hline
\end{tabular}

Fonte: Levantamento STF 2004

Como a prática contábil tem se pautado no disclosure desses valores somente quando próxima ao seu efetivo pagamento, os dados levantados pelo STF foram confrontados com os dados extraídos do SISTN de 2004 a 2009 (último ano de informação disponível) (Tabela 2), em função de as decisões proferidas não repercutirem imediatamente nas contas públicas brasileiras.

Tabela 2 - Precatórios Estaduais - Valores em r\$ contabilizados nos balanços patrimoniais de 2004 a 2009

\begin{tabular}{|c|c|c|c|c|c|c|}
\hline UF & 2004 & 2005 & 2006 & 2007 & 2008 & 2009 \\
\hline $\mathrm{AC}$ & 34.129 .530 & 46.279 .556 & 47.774 .891 & 49.646 .275 & - & 50.514 .104 \\
\hline $\mathrm{AL}$ & - & - & - & - & - & - \\
\hline $\mathrm{AM}$ & - & - & - & - & - & - \\
\hline AP & - & - & - & - & 833.981 .244 & - \\
\hline $\mathrm{BA}$ & 661.771 .014 & 640.401 .155 & 662.498 .225 & 746.790 .156 & - & 832.461 .507 \\
\hline $\mathrm{CE}$ & - & - & - & - & - & - \\
\hline DF & - & - & 2.808 .741 .615 & 3.710 .435 .271 & 654.741 .461 & - \\
\hline ES & - & - & 114.230 .192 & - & - & 635.013 .070 \\
\hline $\mathrm{GO}$ & - & - & - & - & - & - \\
\hline MA & - & - & - & - & 1.423 .957 .268 & - \\
\hline $\mathrm{MG}$ & - & 1.405 .566 .797 & 1.457 .138 .700 & 1.253 .675 .465 & - & 26.180 .493 \\
\hline MS & 257.789 .291 & - & - & - & - & - \\
\hline MT & - & - & - & - & - & - \\
\hline $\mathrm{PA}$ & - & - & - & - & - & 14.377 .078 \\
\hline PB & - & - & - & - & 11.729 .296 & - \\
\hline $\mathrm{PE}$ & 13.176 .068 & - & 4.416 .759 & 23.764 .227 & 325.373 .504 & 11.644 .779 \\
\hline $\mathrm{PI}$ & - & - & - & - & 4.109 .218 .540 & 342.296 .021 \\
\hline PR & 724.531 .982 & 1.368 .191 .908 & 2.440 .728 .981 & 2.619 .168 .738 & 2.780 .339 .592 & 4.391 .379 .496 \\
\hline RJ & 1.047 .422 .412 & 1.170 .509 .590 & 1.920 .799 .264 & 2.626 .205 .093 & 349.966 & 3.295 .793 .818 \\
\hline $\mathrm{RN}$ & - & - & 374.188 & 902.323 & - & 2.325 .640 \\
\hline $\mathrm{RO}$ & 201.410 .340 & 193.752 .106 & 192.284 .042 & - & - & - \\
\hline RR & 1.742 .790 & - & - & 10.119 & 2.056 .087 .250 & - \\
\hline $\mathrm{RS}$ & 1.126 .985 .620 & 1.363 .202 .144 & 1.671 .375 .834 & 1.827 .759 .042 & 410.891 .569 & 2.297 .127 .704 \\
\hline $\mathrm{SC}$ & - & - & - & - & 132.913 .886 & 562.521 .167 \\
\hline SE & 33.898 .655 & 37.561 .175 & 78.924 .103 & 89.023 .589 & 17.600 .471 .405 & 213.332 .065 \\
\hline
\end{tabular}




\begin{tabular}{c|c|c|c|c|c|c}
\hline SP & - & 12.067 .059 .166 & 12.768 .471 .239 & 15.436 .519 .151 & 18.888 .127 & 19.198 .830 .440 \\
\hline TO & - & - & 2.276 .375 & 27.569 .616 & 30.411 .258 .750 & 34.876 .641 \\
\hline BR & 4.102 .857 .702 & 18.292 .523 .598 & 24.170 .034 .407 & 28.411 .469 .065 & 60.770 .201 .857 & 31.908 .674 .023 \\
\hline
\end{tabular}

Fonte: Levantamento STF 2004 e dados do SISTN (em R\$)

Ressalta-se que a base de dados do SISTN apresenta valores consolidados relativos a precatórios financeiros e a precatórios não financeiros, estes últimos compostos por duas contas separadas: Precatórios Anteriores a 05/05/2000 e Precatórios a partir de 05/05/2000.

Restringindo a análise ao exercício de 2004, contemplado nas duas tabelas, verifica-se que as decisões judiciais proferidas nos Estados totalizaram $\mathrm{R} \$ 41.637 .184 .177,00$, dos quais apenas $\mathrm{R} \$$ 4.102.857.702,00 encontravam-se evidenciadas no SISTN, representando, os registros, menos de 10\% das decisões proferidas. Estendendo a análise para os períodos subsequentes, verifica-se que há uma evolução nos registros efetuados, mas acompanhado ainda por certa instabilidade: o exercício de 2009 evidencia pouco mais da metade dos valores evidenciados em 2008.

É importante considerar que a estimativa de probabilidade e a classificação de risco devem preceder o registro dos precatórios nas contas públicas. Por meio do histórico de decisão judicial dos precatórios do ente público, é possível obter uma estimativa da probabilidade de a decisão do precatório ser desfavorável à Fazenda Pública.

Com relação à classificação de risco, conforme estabelecido pela Lei 11.768/2009, caberia à Advocacia Geral da União - AGU a responsabilidade de estimar possíveis valores de condenação. Registra-se que entre as competências institucionais da AGU está a orientação normativa e a supervisão técnica quanto aos órgãos jurídicos das entidades a que alude o Capítulo IX do Título II da Lei Complementar 73, além das atividades de consultoria e assessoramento jurídicos ao Poder Executivo (LC n. 73/93 art. $4^{\circ}$ XIII).

A classificação de risco pela AGU também pode ter como base o histórico de decisões que podem desencadear em precatórios, bem como outros aspectos jurídicos e legais. Por meio dessa classificação, é possível identificar o risco associado ao processo que está em tramitação, classificando-o em provável, possível ou remoto. Os processos que estão no início do trâmite, normalmente, seriam classificados como remotos, pois ainda não há indícios e sustentação jurídica para a AGU estimar a probabilidade da decisão. Ao longo do trâmite do processo, com a descrição dos fatos, as audiências e todos os elementos jurídicos, a AGU pode então classificar o precatório além de remoto, como possível e provável.

\section{ANÁLISE DOS RESULTADOS}

\subsection{Influência da legislação vigente}

No caso dos Estados, verifica-se que dos 41 bilhões de precatórios públicos levantados pelo STF em 2004, apenas 4 e 14 bilhões, respectivamente, encontravam-se evidenciados no SISTN em 2004 e em 2005. Tomando os valores dos anos seguintes, verifica-se que o disclosure dos registros contábeis é de 24 bilhões em 2006, 28 bilhões em 2007, 60 bilhões em 2008, reduzindo para 31 bilhões em 2009, mostrando certa instabilidade no disclosure dos valores. Como não há novos dados consolidados e divulgados pelo STF, não há como saber se os precatórios encontram-se atualmente integralmente evidenciados.

Constatou-se, ainda, no período analisado, que do total de 26 estados e Distrito Federal, 21 deles e o Distrito Federal não possuem saldo algum de precatório a pagar contabilizado no ano de 2005. Dos cinco estados que apresentaram saldo, São Paulo foi o que teve disclosure contábil mais próximo dos valores levantados pelo STF (12 bilhões contra 11 bilhões contabilizados).

Para Lima (2008), entre os prováveis motivos que fazem com que os estados e as capitais brasileiras não contabilizem e evidenciem os precatórios em seus passivos, é que esse procedimento 
impactaria os limites de endividamento estabelecidos na LRF. Outro motivo é a exigência do art. 100 $\S 1^{\circ}$ da CF de 1988, que determina que o ente público inclua no seu orçamento créditos necessários para o pagamento de precatórios de um ano para o outro, impactando o fluxo de caixa do ente público no curto prazo.

\subsection{Inobservância dos fundamentos da teoria contábil}

O presente estudo constatou que o tratamento contábil dado aos precatórios atualmente é feito somente quando há condenação judicial e inclusão desses valores na Lei Orçamentária Anual (LOA). Nenhuma provisão é calculada nem registrada anteriormente à etapa do trânsito em julgado.

Na prática, o que se tem é a prevalência do fato gerador jurídico (condenação judicial) e orçamentário (inclusão na LOA) em detrimento ao fato gerador contábil (caracterização do passivo). Como resultado, a inobservância do pressuposto da competência pode levar a disclosure de valores que não refletem a realidade dos compromissos devidos pelo Governo, prejudicando tanto os usuários internos como os usuários externos da informação contábil (gestor governamental, beneficiado pela decisão judicial e a sociedade em geral).

A bibliografia sobre o assunto é escassa e não existem estudos ou achados específicos que possam subsidiar um estudo comparativo.

\subsection{Proposta de disclosure com base em classificação de risco}

Considerando o aspecto qualitativo da tempestividade da informação, uma solução é a avaliação do risco de o processo judicial materializar-se como exigibilidade, cujo papel, conforme comentando anteriormente, caberia à AGU.

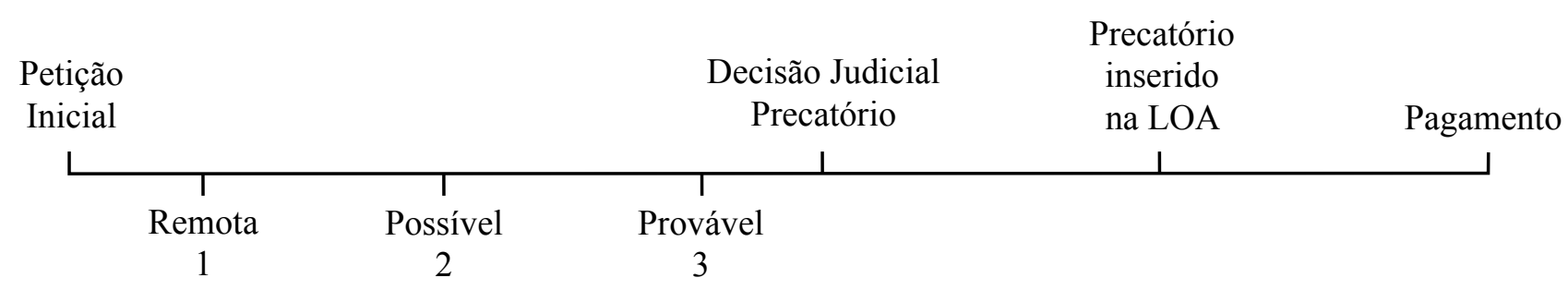

Figura 4 - Classificação do risco do precatório judicial

Diante do exposto, a proposta do presente estudo é que o processo judicial seja contabilizado dependendo da classificação de risco atribuída pela AGU: remota, possível ou provável. No caso da classificação remota (momento 1), esses valores não serão reconhecidos e nem divulgados nas demonstrações contábeis, porque a possibilidade do processo efetivamente se configurar em exigibilidade é insignificante. Portanto, o passivo não estaria caracterizado.

No caso da classificação possível (momento 2), esses valores passam a ser considerados passivos contingentes, devendo o disclosure ser inserido apenas em notas explicativas, permitindo que tanto os usuários internos como os usuários externos da informação contábil estejam a par dos acontecimentos.

Por fim, se provável (momento 3), a provisão deve ser reconhecida como exigibilidade e constar também das notas explicativas. Adota-se nesse caso a máxima: "posso passar a dever e para isso, vou me precaver". Neste momento, estaria caracterizado o passivo, que passaria a impactar as contas públicas, permitindo que os cofres públicos sejam preparados para fazer face aos compromissos devidos pelo Governo.

É importante considerar que o reconhecimento do precatório judicial como passivo, bem como a constituição de provisão para os processos judiciais com classificação provável, impactará significativamente as contas públicas, e, consequentemente, afetará o limite de endividamento 
imposto pela LRF. Nesse caso, para que não haja inobservância do Princípio da Legalidade, há de se discutir como os fundamentos da Teoria Contábil devem ser harmonizados com os dispositivos legais atualmente em vigor.

Outra questão é que se por um lado a incorporação desses valores impacta negativamente as contas públicas, por outro subsidia os gestores quanto ao necessário planejamento para pagamento desses valores, oferecendo aos usuários da informação contábil informações mais próximas da realidade.

\section{CONCLUSÕES}

Neste estudo pretendeu-se analisar o disclosure contábil dos precatórios públicos, verificando a influência da legislação vigente e os fundamentos da doutrina contábil nos procedimentos contábeis adotados.

O estudo mostrou que os dispositivos legais como a LRF e a LOA vêm gerando externalidades no disclosure dos precatórios públicos, fazendo com que deixem de ser observados os fundamentos da Teoria Contábil, mais especificamente os relacionados com a definição do momento do fato gerador do dever de pagar por parte do Governo.

Na maioria dos casos, o gestor, sob a força da lei, acaba por não reconhecer nas contas públicas os valores devidos a título de precatórios, uma vez que não dispõe de recursos financeiros para o pagamento no exercício e muitas vezes já no limite de endividamento permitido. Essa conduta vem afetando a qualidade da informação contábil e prejudicando tanto os usuários internos como os usuários externos, que não dispõem de informações confiáveis em seu processo decisório.

A proposta do presente estudo, tendo como base os fundamentos da Teoria Contábil, é que o processo judicial seja contabilizado antes mesmo da sua caracterização como precatório, de acordo com a classificação de risco atribuído ao processo em tramitação para as contas públicas: se remota, possível ou provável. Essa função caberia institucionalmente à Advocacia Geral da União.

No caso da classificação remota, os processos judiciais não serão reconhecidos e nem divulgados nas demonstrações contábeis, porque a possibilidade de o processo efetivamente se configurar em exigibilidade é insignificante. No caso da classificação possível, esses valores passam a ser considerados passivos contingentes, devendo o disclosure ser apenas em notas explicativas. Por fim, se provável, a provisão deve ser reconhecida como exigibilidade e constar também nas notas explicativas.

Com relação ao impacto significativo que o registro patrimonial desses valores trará para as contas públicas, o estudo sugere a harmonização dos fundamentos da Teoria Contábil com os dispositivos legais atualmente em vigor. Entende-se que a discussão de propostas que flexibilizem o fluxo de caixa para pagamento dos precatórios, como a EC 62, não resolve o problema, porque alivia a pressão sobre o Governo no momento atual, mas não é coerente com o direito líquido e certo daqueles que tem precatório a receber, nem com os futuros gestores e sociedade, que herdarão dívidas passadas.

A mudança do fato jurídico pelo fato contábil com o fim de reconhecer os processos judiciais no momento do fato gerador, conforme preconiza a Teoria Contábil, auxiliará a elaboração do orçamento dos anos seguintes e a representação da realidade nas demonstrações e relatórios públicos de forma tempestiva. O auxílio da Advocacia Geral da União, com o papel de classificação de risco, é primordial para que a nova perspectiva contábil proposta seja levada a efeito.

\section{REFERÊNCIAS}

AHARONY, A.; DOTAN, A., A comparative analysis of auditor, manager and financial analyst interpretations of SFAS 5 disclosure guidelines. Journal of Business Finance \& Accounting, vol. 31, p. 475-504, 2004. 
BRASIL. Constituição (1988). Constituição da República Federativa do Brasil. Atualizada até Emenda Constitucional N. 64 de 4.2.10. Disponível em: <http://www.planalto.gov.br>. Acesso em: 25 mai. 2011.

. Lei N. 11.768/08, de 14 de agosto de 2008. Dispõe sobre a elaboração e execução da Lei de Orçamentária de 2009 e dá outras providências. Diário Oficial da República Federativa do Brasil, Brasília, DF, de 15 de agosto de 2008. Disponível em: <http://www.planalto.gov.br>. Acesso em: 25 mai. 2011.

. Lei Complementar N. 73, de 10 de fevereiro de 1993. Institui a Lei Orgânica da AdvocaciaGeral da União e dá outras providências. Disponível em: <http://www.planalto.gov.br $>$. Acesso em: 25 mai. 2011.

. Lei Complementar N. 101, de 4 de maio de 2000. Estabelece normas de finanças públicas voltadas para a responsabilidade na gestão fiscal e dá outras providências. Diário Oficial da República Federativa do Brasil, Brasília, DF, de 05 de maio de 2000. Disponível em: <http://www.planalto. gov.br>. Acesso em: 25 mai. 2011.

. Plano de contas da Administração Pública Federal de 14 de abril de 2010. Disponível em: $<$ http://www.tesouro.fazenda.gov.br/contabilidade_governamental/download/Pcontas.pdf $>$. Acesso em: 25 mai. 2011.

. Portaria STN nº 664, de 30 de novembro de 2010. Manual de Contabilidade Aplicada ao Setor Público. Parte II - Procedimentos Contábeis Patrimoniais. Aplicado à União, Estados, Distrito Federal e Municípios. Válido para o exercício de 2011. 3. ed. Disponível em: <http://www.tesouro. fazenda.gov.br>. Acesso em: 25 mai. 2011.

. Resolução do Senado Federal N. 40, de 20 de dezembro de 2001. Dispõe sobre os limites globais para o montante da dívida pública consolidada e da dívida pública mobiliária dos Estados, do Distrito Federal e dos Municípios, em atendimento ao disposto no art. 52, VI e IX, da Constituição Federal.

. Resolução do Senado Federal N. 43, de 21 de dezembro de 2001. Dispõe sobre as operações de crédito interno e externo dos Estados, do Distrito Federal e dos Municípios, inclusive concessão de garantias, seus limites e condições de autorização, e dá outras providências.

CONSELHO FEDERAL DE CONTABILIDADE. Resolução $n^{\circ} 1.121$, de 28 de março de 2008. Dispõe sobre a Estrutura Conceitual para a Elaboração e Apresentação das Demonstrações Contábeis. Disponível em: <http://www.cfc.org.br>. Acesso em: 25 mai. 2011.

CUNHA, Antonio Geraldo. Dicionário etimológico Nova Fronteira da língua portuguesa. Rio de Janeiro: Nova Fronteira, 1986.

DU, Ning; KEVIN, Stevens. Numeric-to-verbal translation of probability expressions in SFAS 5. Managerial Auditing Journal. Vol. 26 N. 3, p. 248-262, 2011.

FASB - Financial Accounting Standards Board. SFAS 5 - Accounting for Contingencies. Disponível em: <http://www.fasb.org/st/summary/stsum133.shtml>. Acesso em: 5 mai. 2011. 
FLOWER, John. Global Financial Reporting Palgrave. New York, 2002.

HARADA, Kiyoshi. Precatório Judicial - Parecer. RIDA N. 30 - Assunto Especial - Doutrina, Jun. 2008.

HOFFMAN, V.B.; PATTON, J.M., How are loss contingency accruals affected by alternative reporting criteria and incentives? Journal of Accounting and Public Policy, vol. 21, p. 151-67, 2002.

IFAC - INTERNACIONAL FEDERATION OF ACCOUNTANTS. IPSAS 19 - Provisions, Contingent Liabilities And Contingent Assets. 2010 IFAC Handbook of International Public Sector Accounting Pronouncements. New York: IFAC, 2010. Disponível em: $<$ http://web.ifac.org>. Acesso em: 25 mai. 2011.

LAPSLEY, Irvine, Research in Public Sector Accounting: An Appraisal, Accounting, Auditing \& Accountability Journal, vol. 1 Iss: 1, p. 21 - 33, 1988.

LIMA, Diana Vaz de. Por que as contas públicas não fecham? Fenacon em Serviços - Jan/Fev 2008.

NELSON, M.W.; KINNEY, W.R., The effect of ambiguity on loss contingency reporting judgments. Accounting Review, vol. 72 no. 2, p. 257-74, 1997.

NIYAMA, Jorge Katsumi; SILVA, César Augusto Tibúrcio. Teoria da Contabilidade. São Paulo: Atlas, 2008.

REIMERS, J.L., Additional evidence on the need for disclosure reform. Accounting Horizons, vol. 6 no. 1, p. 36-41, 1992.

SMITH, Peter. The Use of Performance Indicators in the Public Sector. Journal of the Royal Statistical Society. Series A (Statistics in Society), Vol. 153, No. 1, p. 53-72, 1990.

SUPREMO TRIBUNAL FEDERAL. Levantamento realizado em 2004. Disponível em: <http:// www2.oabsp.org.br/asp/comissoes/precatorios/noticias/pop67.pdf >. Acesso em: 25 mai. 2011.

WINDSCHITL, P.D.; WELLS, L.G. Measuring psychological uncertainty: verbal versus numeric methods. Journal of Experimental Psychology: Applied, vol. 2, p. 343-64, 1996. 